\title{
UTJECAJ KULTIVARA, INOKULACIJE SJEMENA I NAVODNJAVANJA NA AGRONOMSKA SVOJSTVA SOJE U ISTOČNOJ HRVATSKOJ
}

\author{
INFLUENCE OF CULTIVAR, SEED INOCULATION AND \\ IRRIGATION ON SOYBEAN AGRONOMIC PROPERTIES \\ IN EASTERN CROATIA
}

Irena Rapčan, Daria Galić Subašić, Sonja Grljušić, Monika Marković

\section{SAŽETAK}

Provedeno je preliminarno poljsko istraživanje na dvije lokacije s ciljem utvrđivanja utjecaja kultivara, inokulacije sjemena i navodnjavanja na poljsko nicanje, broj mahuna po biljci, broj zrna po mahuni, masu 1000 zrna, prinos zrna i koncentraciju bjelančevina u zrnu soje u uvjetima istočne Hrvatske. Utvrđen je značajan utjecaj kultivara, inokulacije sjemena i navodnjavanja na sva promatrana svojstva, izuzev poljskog nicanja na što su značajno utjecali inokulacija i navodnjavanje. Značajne interakcije ispitivanih faktora nisu utvrđene samo za poljsko nicanje. U cilju smanjenja troškova mineralnih gnojiva (prvenstveno dušičnih) i očuvanja okoliša te zbog sve sušnije klime trebalo bi provesti istraživanja o utjecaju inokulanta Nitrobakterin i navodnjavanja na svojstva različitih kultivara soje u različitim agroekološkim uvjetima.

Ključne riječi: soja, kultivar, inokulacija sjemena, navodnjavanje, prinos zrna

\begin{abstract}
Preliminary field research was carried out at two sites to determine the influence of cultivars, inoculation of seed and irrigation on field emergence, number of pods per plant, number of grains per pod, 1000 grain mass, yield and protein content of soybean grain in eastern Croatia. Significant influence of cultivars, inoculation of seeds and irrigation on all observed properties was determined, with the exception of field emergence, which was significantly influenced by inoculation and irrigation. Significant interactions of the investigated factors were not found only for the field emergence. Research on
\end{abstract}


Irena Rapčan i sur.: Utjecaj kultivara, inokulacije sjemena i navodnjavanja na agronomska svojstva soje $u$ istočnoj Hrvatskoj

the influence of Nitrobacterin inoculum and irrigation on the properties of different soybean cultivars should be carried out under different agroecological conditions in order to reduce the costs of mineral fertilizers (primarily nitrogen) and environmental preservation, and in the wake of the drier climate.

Key words: soybean, cultivar, seed inoculation, irrigation, grain yield

\section{UVOD}

Soja se 2014. godine u Republici Hrvatskoj uzgajala na 47.104 ha $\mathrm{s}$ prosječnim prinosom zrna od 2,79 $\mathrm{t} \mathrm{ha}^{-1}$ (Državni zavod za statistiku Republike Hrvatske, http://www.dzs.hr), koji u EU iste godine iznosi $3,23 \mathrm{t} \mathrm{ha}^{-1}$ (www.fao.org.faostat). Slijedom toga postavlja se pitanje mogu li se agrotehnikom (izborom kultivara, inokulanta, rate navodnjavanja i dr.) povećati prinosi u istočnoj Hrvatskoj. U proizvodnji treba upotrijebiti priznati kultivar prilagođen i provjeren na užem području, a inokulaciju sjemena prije sjetve treba smatrati obaveznom i učinkovitom mjerom u tehnologiji proizvodnje soje (Vratarić i Sudarić, 2000.). Autorice također navode da soja treba velike količine vode, a posebno je osjetljiva na nedostatak vode $u$ fazi cvatnje, oplodnje, stvaranja mahuna i nalijevanja zrna. Cilj rada je utvrditi utjecaj kultivara, inokulacije sjemena i navodnjavanja na poljsko nicanje, broj mahuna po biljci, broj zrna po mahuni, masu 1000 zrna, prinos zrna soje i sadržaj bjelančevina u zrnu u uvjetima istočne Hrvatskoj.

\section{MATERIJAL I METODE}

Poljski pokus postavljen je 2014. godine na dvije lokacije istočne Hrvatske. $\mathrm{Na}$ lokaciji Antunovac $\left(45,53^{\circ} \mathrm{N}, 18,73^{\circ} \mathrm{E}, 89 \mathrm{~m}\right.$ nadmorske visine) tlo je lesivirani semiglej na praporu, dok je tlo na lokaciji Cerić $\left(45,46^{\circ} \mathrm{N}, 18,82^{\circ} \mathrm{E}\right.$, $87 \mathrm{~m}$ nadmorske visine) eutrično smeđe na praporu (http://pedologija.com.hr). Pokus je postavljen po shemi split-split s tri faktora i četiri ponavljanja. Veličina osnovne parcele iznosi $5 \mathrm{~m}^{2}$, razmak između parcela $20 \mathrm{~cm}$, a zaštitni pojas $1 \mathrm{~m}$. Soja (Glycine max (L.) Merrill) je posijana ručno, na međuredni razmak od $40 \mathrm{~cm}$ i razmak u redu $10 \mathrm{~cm}$ (u normi sjetve od 300000 biljaka po hektaru). Prvi faktor je kultivar soje $(\mathrm{K})$ : Ika $\left(\mathrm{K}_{1}\right)$ i Tena $\left(\mathrm{K}_{2}\right)$. Oba kultivara pripadaju skupini dozrijevanja 0 -I. Drugi faktor je inokulacija sjemena (I): bez inokulacije $\left(\mathrm{I}_{0}\right)$ i inokulacija inokulantom Nitrobakterin $\left(\mathrm{I}_{1}\right)$. Treći faktor je navodnjavanje $(\mathrm{N})$ : bez navodnjavanja $\left(\mathrm{N}_{0}\right)$ i s navodnjavanjem $\left(\mathrm{N}_{1}\right)$, pri čemu je rata 
Irena Rapčan i sur.: Utjecaj kultivara, inokulacije sjemena i navodnjavanja na agronomska svojstva soje u istočnoj Hrvatskoj

navodnjavanja ovisila o uvjetima lokacije. Nakon nicanja utvrđen je sklop, a nakon žetve broj mahuna po biljci, broj zrna po mahuni, masa 1000 zrna i prinos zrna svake osnovne parcele i ponavljanja. NIT metodom (Infratec 1241 Analyzer, Foss Tecator) određena je koncentracija bjelančevina u zrnu iz prosječnog uzorka zrna po tretmanima. Dobiveni podaci obrađeni su u programu Statistica 13.2. (TIBCO Software Inc, 2017.). Prosjeci tretmana uspoređeni su korištenjem LSD testa. Osnovni klimatski pokazatelji u vegetaciji uspoređeni su s višegodišnjim prosjecima na obje lokacije (http://www.dhmz.htnet.hr). Prosjek srednjih mjesečnih temperatura zraka za mjesece vegetacije (travanj-rujan 2014.) na lokaciji Antunovac nije značajno odstupao od višegodišnjeg prosjeka na lokaciji Antunovac (Tablica 1.). Variranja oborina bila su izraženija. Sušno razdoblje u ovom području inače nastupa u srpnju, ali je 2014. godine nešto manji nedostatak oborina uočen tek u kolovozu. Kako se soja tada nalazila u fazi nalijevanja zrna, provedeno je navodnjavanje u obroku od $30 \mathrm{~mm}$. Ni na lokaciji Cerić (Tablica 2.) prosjek srednjih mjesečnih temperatura zraka u vegetaciji soje u 2014. godini nije se značajno razlikovao od višegodišnjeg prosjeka. Međutim, količina oborina tijekom vegetacije soje premašivala je višegodišnji prosjek za čak 232,7 mm. U lipnju, kada je soja bila u fazi cvatnje, zabilježeno je 49,6 mm manje oborina od višegodišnjeg prosjeka, koji iznosi 111,2 mm, te je provedeno navodnjavanje u obroku od $40 \mathrm{~mm}$.

Tablica 1. Srednja mjesečna temperatura zraka u 2014. godini i višegodišnji (1981. - 2010.) prosjek za mjesece vegetacije soje za lokaciju Antunovac

Table 1 Mean monthly air temperatures in 2014 and long term average (1981 -2010) for the months of growing soybean for the location Antunovac

\begin{tabular}{|l|c|c|c|c|}
\hline \multirow{2}{*}{ Mjesec } & \multicolumn{2}{|c|}{ Srednja mjesečna temperatura zraka, ${ }^{\circ} \mathrm{C}$} & \multicolumn{2}{c|}{ Mjesečna količina oborina, $\mathrm{mm}$} \\
\cline { 2 - 5 } & $2014 . \mathrm{g}$. & $1981 .-2010$. & $2014 . \mathrm{g}$. & $1981 .-2010$. \\
\hline Travanj & 13,2 & 11,8 & 81,3 & 52,4 \\
\hline Svibanj & 16,1 & 17,1 & 161,4 & 63,9 \\
\hline Lipanj & 20,5 & 20,1 & 91,0 & 87,1 \\
\hline Srpanj & 21,8 & 22,0 & 66,4 & 56,0 \\
\hline Kolovoz & 20,8 & 21,3 & 54,3 & 68,3 \\
\hline Rujan & 17,0 & 16,7 & 68,9 & 62,9 \\
\hline & Prosjek: $18,3{ }^{\circ} \mathrm{C}$ & Prosjek: $18,2{ }^{\circ} \mathrm{C}$ & Ukupno: $523,3 \mathrm{~mm}$ & Ukupno: $390,6 \mathrm{~mm}$ \\
\hline
\end{tabular}


Irena Rapčan i sur.: Utjecaj kultivara, inokulacije sjemena i navodnjavanja na agronomska svojstva soje $u$ istočnoj Hrvatskoj

Tablica 2. Srednja mjesečna temperatura zraka u 2014. godini i višegodišnji (1981. - 2010.) prosjek za mjesece vegetacije soje za lokaciju Cerić

Table 2 Mean monthly air temperatures in 2014 and long term average (1981 - 2010) for the months of growing soybean for the location Cerić

\begin{tabular}{|l|c|c|c|c|}
\hline \multirow{2}{*}{ Mjesec } & \multicolumn{2}{|c|}{ Srednja mjesečna temperatura zraka, ${ }^{\circ} \mathrm{C}$} & \multicolumn{2}{c|}{ Mjesečna količina oborina, $\mathrm{mm}$} \\
\cline { 2 - 5 } & $2014 . \mathrm{g}$. & $1981 .-2010$. & $2014 . \mathrm{g}$. & $1981 .-2010$. \\
\hline Travanj & 13,4 & 12,3 & 96,7 & 61,6 \\
\hline Svibanj & 16,4 & 17,6 & 179,0 & 72,5 \\
\hline Lipanj & 20,8 & 20,6 & 61,6 & 111,2 \\
\hline Srpanj & 22,4 & 22,6 & 89,7 & 63,4 \\
\hline Kolovoz & 21,2 & 21,8 & 129,7 & 59,5 \\
\hline Rujan & 17,1 & 17,2 & 100,3 & 56,1 \\
\hline & Prosjek: $18,6{ }^{\circ} \mathrm{C}$ & Prosjek: $18,7^{\circ} \mathrm{C}$ & Ukupno: $657,0 \mathrm{~mm}$ & Ukupno: $424,3 \mathrm{~mm}$ \\
\hline
\end{tabular}

U jesen 2013. godine obavljeno je oranje na obje lokacije. Tanjuranje $\mathrm{i}$ dopunska obrada tla obavljeni su krajem ožujka i početkom travnja 2014. godine, a sjetva 11. travnja (Antunovac) i 12. travnja (Cerić) iste godine. Ručna berba mahuna obavljena je 30. rujna na lokaciji Antunovac i sutradan na lokaciji Cerić. Gnojidba te zaštita od bolesti i štetnika nisu provedene. Zaštita od korova provedena je ručno u dva navrata, jer nije zabilježen jači razvoj korova.

\section{REZULTATI I RASPRAVA}

Početkom svibnja uočeno je nicanje, a u prvoj dekadi lipnja početak cvatnje na obje lokacije. Prve mahune pojavile su se početkom srpnja. $\mathrm{Na}$ poljsko nicanje soje značajno su $(\mathrm{P}=1 \%)$ utjecali inokulacija sjemena $\mathrm{i}$ navodnjavanje (Tablica 3.). Najniže poljsko nicanje uočeno je u tretmanu bez inokulacije sjemena na obje lokacije, a najviše u tretmanu inokulacije sjemena na obje lokacije. Ovi rezultati u skladu su s rezultatima brojnih autora (Prijić i Jovanović, 1994.; Vieira i sur., 2004.; Colet i sur., 2004.). Prosječan broj mahuna po biljci kroz tretmane pokusa na lokaciji Antunovac iznosi 30,11, što je vrlo slično prosječnom broju mahuna po biljci na lokaciji Cerić $(29,51)$. Bilgili i sur. (2005.) dobili su znatno bolje rezultate za ovu komponentu prinosa (47,9-61,6 mahuna po biljci). Svi ispitivani faktori djelovali su značajno na razini $1 \%$ (Tablica 4.). Na obje lokacije dobivene su i značajne interakcije $(\mathrm{P}=1 \%)$ sva tri faktora te na lokaciji Antunovac interakcija inokulacije sjemena i 
Irena Rapčan i sur.: Utjecaj kultivara, inokulacije sjemena i navodnjavanja na agronomska svojstva soje u istočnoj Hrvatskoj

navodnjavanja, a na lokaciji Cerić interakcija kultivara i inokulacije. Najmanji broj mahuna po biljci na obje lokacije dobiven je na tretmanu bez inokulacije sjemena, a najveći broj tretman inokulacije sjemena. Vrijednosti na tretmanu navodnjavanja značajno su veće nego u kontroli, ali unutar raspona kojeg navode Josipović i sur. (2011.). Kultivar Ika imao je veći broj zrna po mahuni od kultivara Tena na obje lokacije (Tablica 5.). Na ovo svojstvo statistički značajno $(\mathrm{P}=1 \%)$ djelovali su svi ispitivani faktori, kao i njihove interakcije, na obje lokacije.

Tablica 3. Prosječne vrijednosti poljskog nicanja (\%) za svaki tretman po lokacijama $s$ pripadajućim $F$-testom i LSD $(p=0,05$ i $p=0,01)$

Table 3 Average values of field emergence (\%) for each treatment over locations with belonging $F$-test and LSD (at $p=0.05$ and $p=0.01$ )

\begin{tabular}{|c|c|c|c|c|c|c|}
\hline Faktor/ Lokacija & \multicolumn{3}{|c|}{ Antunovac } & \multicolumn{3}{|c|}{ Cerić } \\
\hline Kultivar (K): & \multicolumn{3}{|c|}{$\begin{array}{l}80,38 \\
81,13\end{array}$} & \multicolumn{3}{|c|}{$\begin{array}{l}79,44 \\
78,88\end{array}$} \\
\hline F-test & \multicolumn{3}{|c|}{0,557} & \multicolumn{3}{|c|}{0,393} \\
\hline $\begin{array}{r}\text { LSD } 0,05 \\
0,01\end{array}$ & \multicolumn{3}{|c|}{$\begin{array}{l}2,812 \\
2,075\end{array}$} & \multicolumn{3}{|c|}{$\begin{array}{l}\text { n.s. } \\
\text { n.s. }\end{array}$} \\
\hline $\begin{array}{l}\text { Inokulacija } \\
\text { sjemena (I): }\end{array}$ & \multicolumn{3}{|c|}{$\begin{array}{l}73,94 \\
87,56\end{array}$} & \multicolumn{3}{|c|}{$\begin{array}{l}72,88 \\
85,44\end{array}$} \\
\hline F-test & \multicolumn{3}{|c|}{$183,727 * *$} & \multicolumn{3}{|c|}{$195,805 * *$} \\
\hline $\begin{array}{r}\text { LSD } 0,05 \\
0,01\end{array}$ & \multicolumn{3}{|c|}{$\begin{array}{l}2,812 \\
2,075\end{array}$} & \multicolumn{3}{|c|}{$\begin{array}{l}2,511 \\
1,853\end{array}$} \\
\hline $\begin{array}{ll}\text { Navodnjavanje (N): } & \mathrm{N}_{0} \\
& \mathrm{~N}_{1}\end{array}$ & \multicolumn{3}{|c|}{$\begin{array}{l}78,88 \\
82,63\end{array}$} & \multicolumn{3}{|c|}{$\begin{array}{l}77,56 \\
80,75\end{array}$} \\
\hline F-test & \multicolumn{3}{|c|}{$13,918 * *$} & \multicolumn{3}{|c|}{$12,606^{* *}$} \\
\hline $\begin{array}{r}\text { LSD } 0,05 \\
0,01\end{array}$ & \multicolumn{3}{|c|}{$\begin{array}{l}2,812 \\
2,075\end{array}$} & \multicolumn{3}{|c|}{$\begin{array}{l}2,511 \\
1,853\end{array}$} \\
\hline Interakcije: & F-test & LSD 0,05 & LSD 0,01 & F-test & LSD 0,05 & LSD 0,01 \\
\hline $\mathrm{K} \times \mathrm{I}$ & 0,387 & 3,976 & 2,934 & 1,401 & n.s. & n.s. \\
\hline $\mathrm{K} \times \mathrm{N}$ & 0,062 & 3,976 & 2,934 & 1,401 & n.s. & n.s. \\
\hline I x N & 0,758 & 3,976 & 2,924 & 0,237 & n.s. & n.s. \\
\hline $\mathrm{K} \times \mathrm{I} \times \mathrm{N}$ & 0,758 & 5,623 & 4,149 & 3,029 & n.s. & n.s. \\
\hline
\end{tabular}

$\mathrm{K}_{1}=\mathrm{Ika}, \mathrm{K}_{2}=$ Tena; $\mathrm{I}_{0}$ = bez inokulacije sjemena, $\mathrm{I}_{1}$ = inokulacija sjemena;

$\mathrm{N}_{0}=$ bez navodnjavanja, $\mathrm{N}_{1}=$ navodnjavanje; * - $95 \%$ značajnosti, ** - $99 \%$ značajnosti. 
Irena Rapčan i sur.: Utjecaj kultivara, inokulacije sjemena i navodnjavanja na agronomska svojstva soje $u$ istočnoj Hrvatskoj

Tablica 4. Prosječne vrijednosti broja mahuna po biljci za svaki tretman po lokacijama s pripadajućim F-testom i LSD $(p=0,05$ i $p=0,01)$

Table 4 Average values of pod numbers per plant for each treatment over locations with belonging $F$-test and LSD (at $p=0.05$ and $p=0.01$ )

\begin{tabular}{|c|c|c|c|c|c|c|}
\hline Faktor/ Lokacija & \multicolumn{3}{|c|}{ Antunovac } & \multicolumn{3}{|c|}{ Cerić } \\
\hline Kultivar (K): & \multicolumn{3}{|c|}{$\begin{array}{l}28,71 \\
31,51\end{array}$} & \multicolumn{3}{|c|}{$\begin{array}{l}27,83 \\
31,19\end{array}$} \\
\hline F-test & \multicolumn{3}{|c|}{$143,117 * *$} & \multicolumn{3}{|c|}{$248,639 * *$} \\
\hline $\begin{array}{r}\text { LSD } 0,05 \\
0,01\end{array}$ & \multicolumn{3}{|c|}{$\begin{array}{l}0,626 \\
0,484\end{array}$} & \multicolumn{3}{|c|}{$\begin{array}{l}0,596 \\
0,440\end{array}$} \\
\hline $\begin{array}{l}\text { Inokulacija } \\
\text { sjemena (I): }\end{array}$ & \multicolumn{3}{|c|}{$\begin{array}{l}27,84 \\
32,38\end{array}$} & \multicolumn{3}{|c|}{$\begin{array}{l}27,43 \\
31,58\end{array}$} \\
\hline F-test & \multicolumn{3}{|c|}{$373,147 * *$} & \multicolumn{3}{|c|}{$378,754 * *$} \\
\hline $\begin{array}{r}\text { LSD } 0,05 \\
0,01\end{array}$ & \multicolumn{3}{|c|}{$\begin{array}{l}0,626 \\
0,484\end{array}$} & \multicolumn{3}{|c|}{$\begin{array}{l}0,596 \\
0,440\end{array}$} \\
\hline $\begin{array}{ll}\text { Navodnjavanje (N): } & \mathrm{N}_{0} \\
& \mathrm{~N}_{1}\end{array}$ & \multicolumn{3}{|c|}{$\begin{array}{l}28,43 \\
31,79\end{array}$} & \multicolumn{3}{|c|}{$\begin{array}{l}28,18 \\
30,84\end{array}$} \\
\hline F-test & \multicolumn{3}{|c|}{$206,238 * *$} & \multicolumn{3}{|c|}{$155,898 * *$} \\
\hline $\begin{array}{r}\text { LSD } 0,05 \\
0,01\end{array}$ & \multicolumn{3}{|c|}{$\begin{array}{l}0,626 \\
0,484\end{array}$} & \multicolumn{3}{|c|}{$\begin{array}{l}0,596 \\
0,440\end{array}$} \\
\hline Interakcije: & F-test & LSD 0,05 & LSD 0,01 & F-test & LSD 0,05 & LSD 0,01 \\
\hline $\mathrm{K} \times \mathrm{I}$ & 0,120 & 0,928 & 0,928 & $7,925 * *$ & 0,843 & 0,622 \\
\hline $\mathrm{K} \times \mathrm{N}$ & 2,826 & 0,685 & 0,685 & 0,285 & n.s. & n.s. \\
\hline $\mathrm{I} \times \mathrm{N}$ & $8,759 * *$ & 0,928 & 0,685 & 0,870 & n.s. & n.s. \\
\hline $\mathrm{K} \times \mathrm{I} \times \mathrm{N}$ & $30,412 * *$ & 1,312 & 0,968 & $13,208^{* *}$ & 1,193 & 0,880 \\
\hline
\end{tabular}

$\mathrm{K}_{1}=\mathrm{Ika}, \mathrm{K}_{2}=$ Tena; $\mathrm{I}_{0}=$ bez inokulacije sjemena, $\mathrm{I}_{1}=$ inokulacija sjemena;

$\mathrm{N}_{0}$ = bez navodnjavanja, $\mathrm{N}_{1}$ = navodnjavanje; * $-95 \%$ značajnosti, ** - $99 \%$ značajnosti.

Dobiveni rezultati nešto su niži od rezultata za broj zrna po mahuni od 2,6 do 2,9, koji navode Bilgili i sur. (2005.). Tablica 6. pokazuje prosječne vrijednosti za masu 1000 zrna. 
Irena Rapčan i sur.: Utjecaj kultivara, inokulacije sjemena i navodnjavanja na agronomska svojstva soje u istočnoj Hrvatskoj

Tablica 5. Prosječne vrijednosti broja zrna po mahuni za svaki tretman po lokacijama s pripadajućim F-testom i LSD $(p=0,05$ i $p=0,01)$

Table 5 Average values of grain numbers per pod for each treatment over locations with belonging $F$-test and LSD (at $p=0.05$ and $p=0.01$ )

\begin{tabular}{|c|c|c|c|c|c|c|}
\hline Faktor/ Lokacija & \multicolumn{3}{|c|}{ Antunovac } & \multicolumn{3}{|c|}{ Cerić } \\
\hline Kultivar (K): & \multicolumn{3}{|c|}{$\begin{array}{l}2,31 \\
2,02 \\
\end{array}$} & \multicolumn{3}{|c|}{$\begin{array}{l}2,31 \\
2,02\end{array}$} \\
\hline F-test & \multicolumn{3}{|c|}{$66,245^{* *}$} & \multicolumn{3}{|c|}{$66,468 * *$} \\
\hline $\begin{array}{r}\text { LSD } 0,05 \\
0,01\end{array}$ & \multicolumn{3}{|c|}{$\begin{array}{l}0,098 \\
0,073\end{array}$} & \multicolumn{3}{|c|}{$\begin{array}{l}0,098 \\
0,073\end{array}$} \\
\hline $\begin{array}{l}\text { Inokulacija } \\
\text { sjemena (I): }\end{array}$ & \multicolumn{3}{|c|}{$\begin{array}{l}2,27 \\
2,06\end{array}$} & \multicolumn{3}{|c|}{$\begin{array}{l}2,27 \\
2,06\end{array}$} \\
\hline F-test & \multicolumn{3}{|c|}{$33,977 * *$} & \multicolumn{3}{|c|}{$34,564 * *$} \\
\hline $\begin{array}{r}\text { LSD } 0,05 \\
0,01\end{array}$ & \multicolumn{3}{|c|}{$\begin{array}{l}0,098 \\
0,073\end{array}$} & \multicolumn{3}{|c|}{$\begin{array}{l}0,098 \\
0,073\end{array}$} \\
\hline $\begin{array}{ll}\text { Navodnjavanje (N): } & \mathrm{N}_{0} \\
& \mathrm{~N}_{1}\end{array}$ & \multicolumn{3}{|c|}{$\begin{array}{l}2,27 \\
2,07\end{array}$} & \multicolumn{3}{|c|}{$\begin{array}{l}2,27 \\
2,06\end{array}$} \\
\hline F-test & \multicolumn{3}{|c|}{$33,152 * *$} & \multicolumn{3}{|c|}{$33,734 * *$} \\
\hline $\begin{array}{r}\text { LSD } 0,05 \\
0,01\end{array}$ & \multicolumn{3}{|c|}{$\begin{array}{l}0,098 \\
0,073\end{array}$} & \multicolumn{3}{|c|}{$\begin{array}{l}0,098 \\
0,073\end{array}$} \\
\hline Interakcije: & F-test & LSD 0,05 & LSD 0,01 & F-test & LSD 0,05 & LSD 0,01 \\
\hline K x I & $69,761 * *$ & 0,139 & 0,103 & $68,214 * *$ & 0,139 & 0,103 \\
\hline $\mathrm{K} \times \mathrm{N}$ & $17,889 * *$ & 0,139 & 0,103 & $17,717 * *$ & 0,139 & 0,103 \\
\hline I x N & $20,054 * *$ & 0,139 & 0,103 & $20,194 * *$ & 0,139 & 0,103 \\
\hline $\mathrm{K} \times \mathrm{I} \times \mathrm{N}$ & $24,407 * *$ & 0,197 & 0,145 & $25,269 * *$ & 0,197 & 0,145 \\
\hline
\end{tabular}

$\mathrm{K}_{1}=\mathrm{Ika}, \mathrm{K}_{2}=$ Tena; $\mathrm{I}_{0}$ = bez inokulacije sjemena, $\mathrm{I}_{1}$ = inokulacija sjemena;

$\mathrm{N}_{0}=$ bez navodnjavanja, $\mathrm{N}_{1}=$ navodnjavanje; * - 95\% značajnosti, ** - $99 \%$ značajnosti. 
Irena Rapčan i sur.: Utjecaj kultivara, inokulacije sjemena i navodnjavanja na agronomska svojstva soje u istočnoj Hrvatskoj

Tablica 6. Prosječne vrijednosti mase 1000 zrna (g) za svaki tretman po lokacijama $s$ pripadajućim F-testom i LSD $(p=0,05$ i $p=0,01)$

Table 6 Average values of 1000 grain mass (g) for each treatment over locations with belonging $F$-test and LSD (at $p=0.05$ and $p=0.01$ )

\begin{tabular}{|c|c|c|c|c|c|c|}
\hline Faktor/ Lokacija & \multicolumn{3}{|c|}{ Antunovac } & \multicolumn{3}{|c|}{ Cerić } \\
\hline Kultivar (K): & \multicolumn{3}{|c|}{$\begin{array}{l}169,43 \\
176,54\end{array}$} & \multicolumn{3}{|c|}{$\begin{array}{l}170,21 \\
175,80\end{array}$} \\
\hline F-test & \multicolumn{3}{|c|}{$6,292^{*}$} & \multicolumn{3}{|c|}{$21,703 * *$} \\
\hline $\begin{array}{r}\text { LSD } 0,05 \\
0,01\end{array}$ & \multicolumn{3}{|c|}{$\begin{array}{l}7,940 \\
5,859\end{array}$} & \multicolumn{3}{|c|}{$\begin{array}{l}3,355 \\
2,475\end{array}$} \\
\hline $\begin{array}{l}\text { Inokulacija } \\
\text { sjemena (I): }\end{array}$ & \multicolumn{3}{|c|}{$\begin{array}{l}157,49 \\
188,48\end{array}$} & \multicolumn{3}{|c|}{$\begin{array}{l}158,86 \\
187,15\end{array}$} \\
\hline F-test & \multicolumn{3}{|c|}{$119,119 * *$} & \multicolumn{3}{|c|}{$556,132 * *$} \\
\hline $\begin{array}{r}\text { LSD } 0,05 \\
0,01\end{array}$ & \multicolumn{3}{|c|}{$\begin{array}{l}7,940 \\
5,859\end{array}$} & \multicolumn{3}{|c|}{$\begin{array}{l}3,355 \\
2,475\end{array}$} \\
\hline $\begin{array}{ll}\text { Navodnjavanje (N): } & \mathrm{N}_{0} \\
& \mathrm{~N}_{1}\end{array}$ & \multicolumn{3}{|c|}{$\begin{array}{l}168,64 \\
177,33\end{array}$} & \multicolumn{3}{|c|}{$\begin{array}{l}166,54 \\
179,48\end{array}$} \\
\hline F-test & \multicolumn{3}{|c|}{$9,356^{* *}$} & \multicolumn{3}{|c|}{$116,324 * *$} \\
\hline $\begin{array}{r}\text { LSD } 0,05 \\
0,01\end{array}$ & \multicolumn{3}{|c|}{$\begin{array}{l}7,940 \\
5,859\end{array}$} & \multicolumn{3}{|c|}{$\begin{array}{l}3,355 \\
2,475\end{array}$} \\
\hline Interakcije: & F-test & LSD 0,05 & LSD 0,01 & F-test & LSD 0,05 & LSD 0,01 \\
\hline $\mathrm{K} \times \mathrm{I}$ & 1,204 & 11,228 & 8,286 & 2,889 & n.s. & n.s. \\
\hline $\mathrm{K} \times \mathrm{N}$ & 0,482 & 11,228 & 8,286 & 0,087 & n.s. & n.s. \\
\hline I x N & 2,984 & 11,228 & 8,286 & $32,514 * *$ & 4,745 & 3,501 \\
\hline $\mathrm{K} \times \mathrm{I} \times \mathrm{N}$ & 3,974 & 15,879 & 11,718 & $5,587 *$ & 6,710 & n.s. \\
\hline
\end{tabular}

$\mathrm{K}_{1}=\mathrm{Ika}, \mathrm{K}_{2}=$ Tena; $\mathrm{I}_{0}=$ bez inokulacije sjemena, $\mathrm{I}_{1}=$ inokulacija sjemena;

$\mathrm{N}_{0}=$ bez navodnjavanja, $\mathrm{N}_{1}$ = navodnjavanje; * - $95 \%$ značajnosti, ** - $99 \%$ značajnosti.

Iako su na lokaciji Antunovac svi ispitivani faktori djelovali statistički značajno $(\mathrm{P}=1 \%)$, najmanju vrijednost pokazuje tretman bez inokulacije sjemena, a najveću tretman inokulacije sjemena. Isti utjecaj tretmana uočen je i na lokaciji Cerić, uz statistički značajne interakcije inokulacije sjemena i navodnjavanja $(\mathrm{P}=1 \%)$ te interakciju svih triju ispitivanih faktora $(\mathrm{P}=5 \%)$. Razliku u masi 1000 zrna soje bez i s inokulacijom u svojim istraživanjima dobili su Redžepović i sur. (1986.). Sve vrijednosti (kroz tretmane i na obje lokacije) dobivene u ovom ispitivanju uklapaju se u široki raspon $(139,80$ - 
Irena Rapčan i sur.: Utjecaj kultivara, inokulacije sjemena i navodnjavanja na agronomska svojstva soje $u$ istočnoj Hrvatskoj

186,47 g) kojeg navode Prijić i Jovanović (1994.). Prosječni prinos zrna (Tablica 7.) dobiven na lokaciji Antunovac iznosi 2,68 $\mathrm{t} \mathrm{ha}^{-1}$, dok je prinos zrna na lokaciji Cerić manji za $60 \mathrm{~kg} \mathrm{ha}^{-1}$.

Tablica 7. Prosječne vrijednosti prinosa zrna $\left(\mathrm{t} \mathrm{ha}^{-1}\right)$ za svaki tretman po lokacijama $s$ pripadajućim F-testom i LSD $(p=0,05$ i $p=0,01)$

Table 7 Average values of grain yield $\left(\mathrm{t} \mathrm{ha}^{-1}\right)$ for each treatment over locations with belonging LSD and (at $p=0.05$ and $p=0.01$ )

\begin{tabular}{|c|c|c|c|c|c|c|}
\hline Faktor/ Lokacija & \multicolumn{3}{|c|}{ Antunovac } & \multicolumn{3}{|c|}{ Cerić } \\
\hline Kultivar (K): & \multicolumn{3}{|c|}{$\begin{array}{l}2,64 \\
2,71\end{array}$} & \multicolumn{3}{|c|}{$\begin{array}{l}2,57 \\
2,67\end{array}$} \\
\hline F-test & \multicolumn{3}{|c|}{$6,818^{*}$} & \multicolumn{3}{|c|}{$11,056^{* *}$} \\
\hline $\begin{array}{r}\text { LSD } 0,05 \\
0,01\end{array}$ & \multicolumn{3}{|c|}{$\begin{array}{c}0,082 \\
\text { n.s. }\end{array}$} & \multicolumn{3}{|c|}{$\begin{array}{l}0,089 \\
0,066\end{array}$} \\
\hline $\begin{array}{l}\text { Inokulacija } \\
\text { sjemena (I): }\end{array}$ & \multicolumn{3}{|c|}{$\begin{array}{l}2,17 \\
3,18\end{array}$} & \multicolumn{3}{|c|}{$\begin{array}{l}2,12 \\
3,12\end{array}$} \\
\hline F-test & \multicolumn{3}{|c|}{$1203,592 * *$} & \multicolumn{3}{|c|}{$974,555 * *$} \\
\hline $\begin{array}{r}\text { LSD } 0,05 \\
0,01\end{array}$ & \multicolumn{3}{|c|}{$\begin{array}{l}0,082 \\
0,060\end{array}$} & \multicolumn{3}{|c|}{$\begin{array}{l}0,089 \\
0,066\end{array}$} \\
\hline $\begin{aligned} \text { Navodnjavanje }(\mathrm{N}): & \mathrm{N}_{0} \\
& \mathrm{~N}_{1}\end{aligned}$ & \multicolumn{3}{|c|}{$\begin{array}{l}2,52 \\
2,83\end{array}$} & \multicolumn{3}{|c|}{$\begin{array}{l}2,44 \\
2,80\end{array}$} \\
\hline F-test & \multicolumn{3}{|c|}{$116,216^{* *}$} & \multicolumn{3}{|c|}{$122,567 * *$} \\
\hline $\begin{array}{r}\text { LSD } 0,05 \\
0,01\end{array}$ & \multicolumn{3}{|c|}{$\begin{array}{l}0,082 \\
0,060\end{array}$} & \multicolumn{3}{|c|}{$\begin{array}{l}0,089 \\
0,066\end{array}$} \\
\hline Interakcije: & F-test & LSD 0,05 & LSD 0,01 & F-test & LSD 0,05 & LSD 0,01 \\
\hline $\mathrm{K} \times \mathrm{I}$ & $55,396^{* *}$ & 0,116 & 0,085 & $34,895^{* *}$ & 0,126 & 0,093 \\
\hline $\mathrm{K} \times \mathrm{N}$ & $24,190 * *$ & 0,116 & 0,085 & $19,892 * *$ & 0,126 & 0,093 \\
\hline $\mathrm{I} \times \mathrm{N}$ & $7,724 *$ & 0,116 & n.s. & $6,466^{*}$ & 0,126 & n.s. \\
\hline $\mathrm{K} \times \mathrm{I} \times \mathrm{N}$ & 3,554 & n.s. & n.s. & 0,878 & n.s. & n.s. \\
\hline
\end{tabular}

$\mathrm{K}_{1}=\mathrm{Ika}, \mathrm{K}_{2}=$ Tena; $\mathrm{I}_{0}=$ bez inokulacije sjemena, $\mathrm{I}_{1}=$ inokulacija sjemena;

$\mathrm{N}_{0}=$ bez navodnjavanja, $\mathrm{N}_{1}=$ navodnjavanje; * - 95\% značajnosti, ** - $99 \%$ značajnosti.

Sva tri ispitivana faktora na obje lokacije pokazala su se statistički značajnima na razini $1 \%$, izuzev kultivara na lokaciji Antunovac $(\mathrm{P}=5 \%)$. Uočene su i dvije statistički značajne interakcije (na razini 1\%) na obje lokacije (kultivar i inokulacija te kultivar i navodnjavanje) te jedna na razini 5\% (inokulacija i navodnjavanje) na obje lokacije. Prinos zrna po tretmanima 
Irena Rapčan i sur.: Utjecaj kultivara, inokulacije sjemena i navodnjavanja na agronomska svojstva soje $u$ istočnoj Hrvatskoj

iznosio je od 2,17 do 3,18 tha ${ }^{-1}$ na lokaciji Antunovac i od 2,12 do 3,12 $\mathrm{t} \mathrm{ha}^{-1}$ na lokaciji Cerić. Najveći prinos zrna na obje lokacije dobiven je tretmanom inokulacije sjemena, kao i u istraživanju Redžepovića i sur. (1986.). Seneviratne i sur. (2000.) dobili su prinos zrna soje u tretmanu kontrole od $1,458 \mathrm{t} \mathrm{ha}^{-1}$, $\mathrm{u}$ tretmanu dušične gnojidbe $2,693 \mathrm{t} \mathrm{ha}^{-1} \mathrm{i}$ u tretmanu inokulacije $2,882 \mathrm{t} \mathrm{ha}^{-1}$. Komesarović i sur. (2007.) nalaze prosječni prinos dviju kultivara soje (Nada i Ika) bez inokulacije sjemena od 1,94 i 1,97 t ha ${ }^{-1}$, a s inokulacijom od 2,69 do 3,42 i 2,60 do 2,90 t ha ${ }^{-1}$. Sikora i sur. (2008.), Dabić i sur. (2009.) te Sudarić i sur. (2010.) također nalaze značajno povećanje prinosa zrna soje uz inokulaciju bakterijama. Analiza naših podataka pokazala je povećanje prinosa zrna u tretmanu navodnjavanja na obje lokacije, što je u skladu $\mathrm{s}$ rezultatima istraživanja brojnih autora (Balešević-Tubić i sur., 2001., De Costa i Shanmugathasan, 2002., Josipović i sur., 2010., Josipović i sur., 2011., Zhang i sur., 2015., Irmak i Sharma, 2015.). Iz grafikona 1. vidljivo je da se na lokaciji Antunovac sadržaj bjelančevina kretao od 36,68\% (kultivar Tena u kontroli) do 38,88\% (kultivar Ika u inokulaciji sjemena i navodnjavanju). Koncentracija bjelančevina u zrnu na lokaciji Cerić (Grafikon 2.) kretala se od $36,9 \%$ (kultivar Tena u kontroli) do 38,85\% (kultivar Ika u inokulaciji sjemena i navodnjavanju), što je uži raspon od onoga na lokaciji Antunovac.

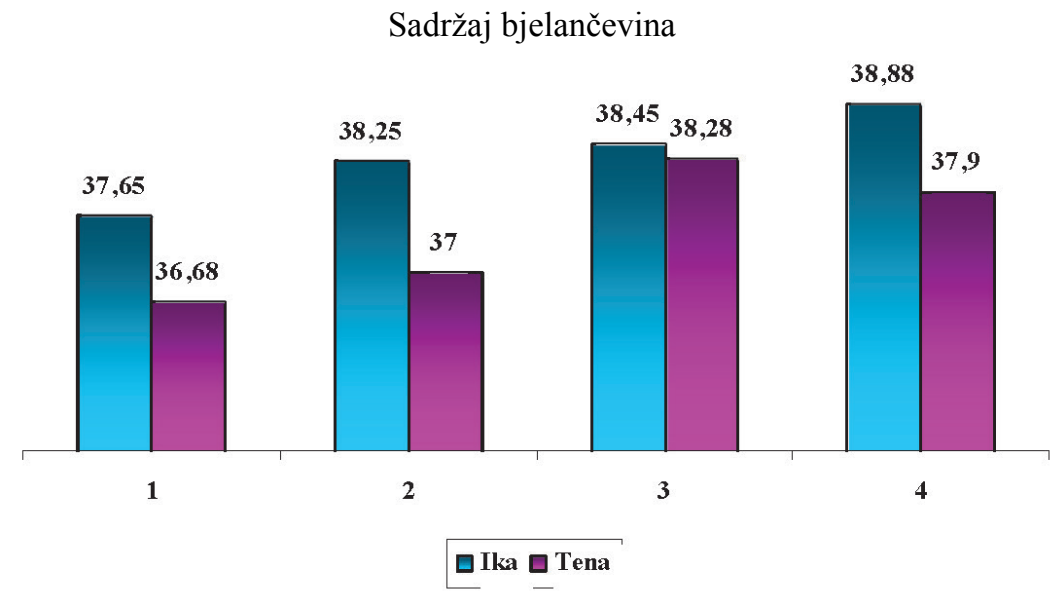

Tretman 1: Kontrola; Tretman 2: Inokulacija; Tretman 3. Navodnjavanje; Tretman 4: Navodnjavanje i inokulacija.

Grafikon 1. Koncentracija bjelančevina (\%) kultivara Ika i Tena na lokaciji Antunovac Graph 1 Protein concentration (\%) of Ika and Tena cultivars at Antunovac location 
Irena Rapčan i sur.: Utjecaj kultivara, inokulacije sjemena i navodnjavanja na agronomska svojstva soje u istočnoj Hrvatskoj

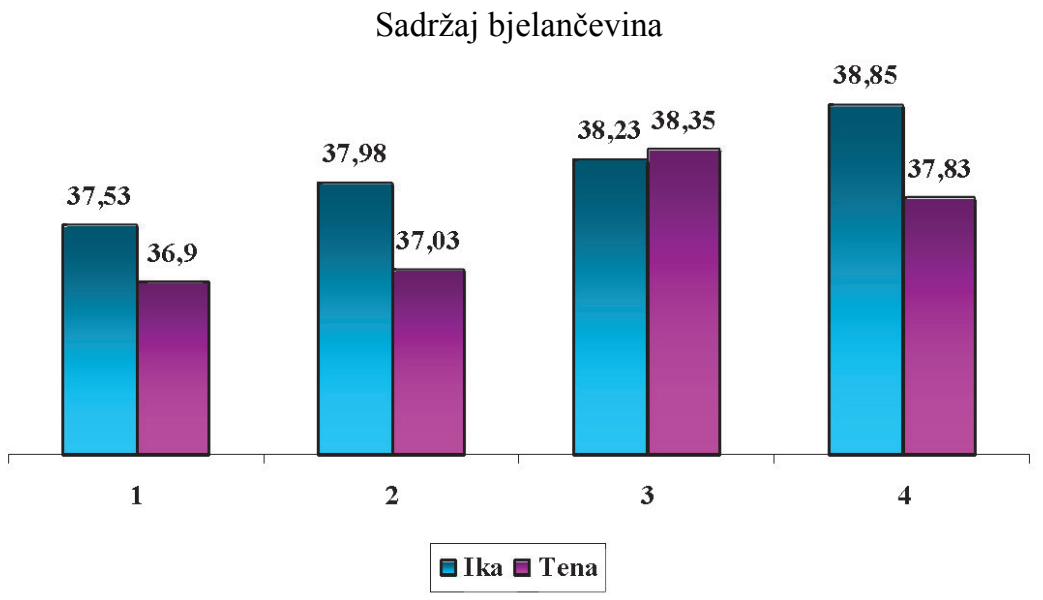

Tretman 1: Kontrola; Tretman 2: Inokulacija; Tretman 3. Navodnjavanje; Tretman 4: Navodnjavanje i inokulacija.

Grafikon 2. Koncentracija bjelančevina (\%) kultivara Ika i Tena na lokaciji Cerić

Graph 2 Protein concentration (\%) of Ika and Tena cultivars at location Cerić

Inokulacija sjemena bakterijama povećava koncentraciju bjelančevina preko 45\% u odnosu na kontrolu (Redžepović i sur., 1986.). Jukić i sur. (2007.) utvrdili su koncentraciju bjelančevina u zrnu tri kultivara soje u dvogodišnjim ispitivanjima od 36,66 do $38,20 \%$ odnosno 33,84 do $35,01 \%$. Sudarić i Vratarić (2008.) nalaze koncentraciju bjelančevina u zrnu kultivara Tena od 41,20 do $41,67 \%$ i kultivara Ika od 39,65-40,77\%, što su nešto veće vrijednosti od naših rezultata. Sikora i sur. (2008.) izvještavaju o koncentraciji bjelančevina u zrnu soje, koja je nešto manja od ili u visini vrijednosti dobivenih u našem istraživanju. Sudarić i sur. (2010.) ispitujući osam genotipova soje bilježe u prosjeku $41,27 \%$ bjelančevina u zrnu. Dušična fiksacija se može poboljšati inokulacijom sjemena superiornim sojevima Bradyrhizobium japonicum (Campo i sur., 2009.), dok navodnjavanje soje ima statistički značajan učinak na ublažavanje štetnih klimatskih utjecaja, posebno suše i ekstremne vrućine (Zhang i sur., 2015.). Naime, Kovačević i sur. (2010.) zaključuju da je značajna varijacija u prinosu jarih poljskih usjeva u Hrvatskoj uglavnom rezultat vremenskih prilika, posebno oborinskog i temperaturnog režima tijekom ljetnih mjeseci. 
Irena Rapčan i sur.: Utjecaj kultivara, inokulacije sjemena i navodnjavanja na agronomska svojstva soje u istočnoj Hrvatskoj

\section{ZAKLJUCAK}

Godina istraživanja bila je vrlo neuobičajena po količini i rasporedu oborina, što je vjerojatno utjecalo na ispitivana svojstva. Poljsko nicanje po tretmanima pokusa iznosilo je od $72,88 \%$ do $87,56 \%$ ovisno o lokaciji, a na ovo svojstvo najviše su utjecali inokulacija sjemena i navodnjavanje, dok kultivar nije imao utjecaja. Na komponente prinosa (broj mahuna po biljci, broj zrna po mahuni i masu 1000 zrna) ispitivani faktori (kultivar, inokulacija sjemena kvržičnim bakterijama i navodnjavanje) različito su utjecali na dvije ispitivane lokacije (Antunovac i Cerić). Prinos zrna bio je niži od vrijednosti navedenih $\mathrm{u}$ literaturi, uz najmanje vrijednosti dobivene $u$ tretmanu bez inokulacije sjemena, a najveće u tretmanu inokulacije sjemena. U cilju smanjenja troškova mineralnih gnojiva (prvenstveno dušičnih) i očuvanja okoliša te zbog sve sušnije klime trebalo bi provesti istraživanja o utjecaju inokulanta Nitrobakterin i navodnjavanja na svojstva različitih kultivara soje u različitim agroekološkim uvjetima.

\section{LITERATURA}

1. Balešević-Tubić, S., Hrustić, M., Milošević, M., Tatić, M., Vujaković, M. (2001): Uticaj suše na kvalitet i prinos sjemena soje. Zbornik radova Naučnog instituta za ratarstvo i povrtlarstvo, Novi Sad, 35: 383-390.

2. Bilgili, U., Sincik, M., Goksoy, A.T., Turan, Z.M., Acikgoz, E. (2005.): Forage and grain yield performance of soybean lines. Journal of Central European Agriculture 6(3): 397402.

3. Campo, R.J., Araujo, R.S., Hungaria, M. (2009.): Nitrogen fixation with the soybean crop in Brazil: Compatibility between seed treatment with fungicides and bradyrhizobial inoculants. Symbiosis 48 (1-3): 154-163.

4. Christou P. (1997.): Biotechnology applied to grain legumes. Field Crops Research 53: 83--97.

5. Colete, J.C.F., Vieira, R.D., Dutra, A.S. (2004.): Electrical conductivity and soybean seedling emergence, Sciencia agricola, 61(4): 386-391.

6. Dabić, K., Kristek, S., Kristek, A., Antunović, M., Brkić, S. (2009.): Prinos i kvaliteta zrna soje u ovisnosti od gnojidbe dušikom i inokulacije sjemena kvržičnim bakterijama i mikoriznim gljivama. Proceedings of 44th Croatian and 4th International Conference of Agriculture, Opatija: 54-58. 
Irena Rapčan i sur.: Utjecaj kultivara, inokulacije sjemena i navodnjavanja na agronomska svojstva soje $u$ istočnoj Hrvatskoj

7. De Costa, W.A.J.M., Shanmugathasan, K.N. (2002.): Physiology of yield determination of soybean (Glycine max (L.) Merr) under different irrigation regimes in the sub-humid zone of Sri Lanka. Field Crops Research 75: 23-35.

8. Irmak, S., Sharma, V. (2015.): Large-scale and long-term trends and magnitudes in irrigated and rainfed maize and soybean water productivity: grain yield and evapotranspiration frequency, crop water use efficiency, and production function. Transactions of the Asabe 58 (1): 103-120.

9. Josipović, M., Plavšić, H., Sudarić, A., Vratarić, M., Liović, I. (2010.): Utjecaj navodnjavanja i gnojidbe dušikom na urod zrna soje Glycine max (L.) Merr. Proceedings of 45th Croatian and 5th International Conference of Agriculture, Opatija: 751-755.

10. Josipović, M., Sudarić, A., Kovačević, V., Marković, M., Plavšić, H., Liović, I. (2011.): Irrigation and nitrogen fertilization influences on properties of soybena (Glycine max (L.) Merr.) varietes. Poljoprivreda 17(1): 9-15.

11. Jukić, G., Guberac, V., Marić, S., Dunković, D. (2007.): Ekonomski aspekti proizvodnje soje u istočnoj Hrvatskoj. Poljoprivreda 13 (2): 23-28.

12. Komesarović, B., Redžepović, S., Blažinkov, M., Sudarić, A., Uher, D., Sikora, S. (2007.): Simbiozna učinkovitost selekcioniranih autohtonih sojeva Bradyrhizobium japonicum. Mljekarstvo 57 (4): 289-302.

13. Kovačević, V., Josipović, M., Kaučić, D., Iljkić, D. (2010.): Weather impacts on yields of maize, sugar beet, soybeans and sunflower. Proceedings of 45th Croatian and 5th International Conference of Agriculture, Opatija: 796-800.

14. Prijić, M.Lj., Jovanović, M. (1994.): Uticaj vigora semena na nicanje i prinos soje. Selekcija i semenarstvo, 1(1): 131-133.

15. Redžepović, S., Strunjak, R., Varga, B., Heneberg, R., Slamić, F., Bašić, F., Šeput, M., Puhalo, D., Dušanić, B. (1986.): Prvi rezultati bakterizacije soje s $\mathrm{Hup}^{+}$sojem Bradyrhizobium japonicum-a u SR Hrvatskoj. Agronomski glasnik 48(1-2): 3-12.

16. Seneviratne, G.; Van Holm, L.H.J.; Ekanayake, E.M.H.G.S. (2000.): Agronomic benefits of rhizobial inoculant use over nitrogen fertilizer application in tropical soybean. Field Crops Research 68: 199-203.

17. Sikora, S., Blažinkov, M., Babić, K., Sudarić, A., Redžepović, S. (2008.): Symbiotic nitrogen fixation and sustainable soybean production. Cereal Research Communications 36 (S): 1483-1486.

18. Sudarić, A., Vratarić, M. (2008.): Značenje, dostignuća i trendovi u oplemenjivanju soje u Poljoprivrednom institutu Osijek. Sjemenarstvo 25 (34): 207-216. 
Irena Rapčan i sur.: Utjecaj kultivara, inokulacije sjemena i navodnjavanja na agronomska svojstva soje $u$ istočnoj Hrvatskoj

19. Sudarić, A., Vratarić, M., Matoša, M., Duvnjak, T., Redžepović, S., Sikora, S. (2010.): Učinak biološke fiksacije dušika na urod i kakvoću zrna različitih genotipova soje. Proceedings of $45^{\text {th }}$ Croatian and $5^{\text {th }}$ International Conference of Agriculture, Opatija: 514 - 518.

20. Vieira, R.D., Scappa Neto, A., Bittencourt, S.R.M., Panobianco, M. (2004.): Electrical conductivity of the seed soaking solution and soybean seedling emergence. Sciencia agricola, 61(2): 164-168.

21. Vratarić, M., Sudarić, A. (2000.): Soja. Poljoprivredni institut Osijek, str. 111114

22. Zhang, T.Y., Lin, X.M., Sassenrath, G.F. (2015.): Current irrigation practices in the central United States reduce drought and extreme heat impacts for maize and soybean, but not for wheat. Science of total environment 508: 331-342.

*** http://pedologija.com.hr (30.10.2014.)

*** http://www.dzs.hr (29.11.2015.)

*** www.dhmz.htnet.hr (29.11.2015.)

*** www.fao.org.faostat (29.11.2015.)

Adrese autora - Author's addresses:

Primljeno - received:

izv. prof. dr.sc. Irena Rapčan

11.04.2019.

e- mail: irapcan@fazos.hr

Daria Galić Subašić, dipl. ing.

doc.dr.sc. Monika Marković

Sveučilište J.J. Strossmayera u Osijeku

Fakultet agrobiotehničkih znanosti Osijek,

Vladimira Preloga 1, Osijek, Hrvatska

dr.sc. Sonja Grljušić

Poljoprivredni institut Osijek,

Južno predgrađe 17, Osijek, Hrvatska 